\title{
EI uso de las TIC en la enseñanza universitaria de la fotografía. Primeros resultados del proyecto de innovación docente de la Universidad de Murcia
}

\author{
The use of ICT in the course "Photography" in university \\ education. First results of a teaching innovation project \\ at the University of Murcia
}

\author{
BorJa Morgado-Aguirre \\ Universidad de Murcia \\ morgado@um.es \\ ELENA LÓPEZ-MARTÍN \\ Universidad de Murcia \\ elenalopezm@hotmail.com \\ SAlvador Conesa-TeJada \\ Universidad de Murcia \\ sconesa@um.es
}

Recibido: 6 de mayo de 2014

Aprobado: 25 de septiembre de 2014

\section{Resumen}

El nuevo marco pedagógico surgido tras la Declaración de Bolonia, el Comunicado de Praga y la implantación del Espacio Europeo de Educación Superior, apuesta significativamente por las Tecnologías de la Información y la Comunicación como parte de la evolución de las metodologías docentes. Las maneras de relacionarse e interactuar entre el docente y el discente han experimentado un asombroso cambio del que surgen nuevas iniciativas de enseñanza basadas, muchas de ellas, en la democratización de los contenidos a través del uso de las TIC.

El presente artículo pretende mostrar los resultados obtenidos hasta el curso 2012/2013 tras la implantación del proyecto de innovación docente titulado "El uso de las TIC aplicadas al aprendizaje autónomo del alumno en la enseñanza universitaria de fotografia. Elaboración de un aula didáctica virtual para la asignatura y estudio de resultados de mejora en la adquisición de habilidades y competencias" desarrollado en la asignatura Dibujo con Luz. Fotografia, perteneciente al Grado en Bellas Artes de la Universidad de Murcia.empírico.

Palabras clave: fotografía, docencia, enseñanza, innovación, virtual.

Morgado-Aguirre, B., López-Martín, E., Conesa-Tejada, S. (2015): El uso de las TIC en la enseñanza universitaria de la fotografia. Primeros resultados del proyecto de innovación docente de la Universidad de Murcia. Arte, Individuo y Sociedad, 27(2) 295-319 


\begin{abstract}
The new pedagogical framework arisen since the Bologna Declaration,the Prague Communiquéand the introduction of the European Higher Education Area (EHEA), encourages, significantly, the use of new Communication and Information Technology to evolve teaching methodologies. The different ways teachers relate to learners have undergone a staggering change from which educational initiatives have emerged. Many of them are based on contents' democratization through the use of ICT.

The current article is intended to show the results obtained until the 2012/2013 academic course, since the implementation of the teaching innovation project entitled "The use of ICT for the students' autonomous learning in the university education of the course Photography. Elaboration of a virtual classroom and results' analysis related to the acquisition of skills and competencies" that has been developed in the course called Draw with light: Photography, belonging to the Fine Arts Degree at the University of Murcia. Keywords: photography, teaching, education, innovation, virtual.
\end{abstract}

Sumario: 1. Justificación y antecedentes, 2. Filosofías y herramientas empleadas para una mayor difusión y accesibilidad de los contenidos educativos, 3. Presentación del proyecto, 4. Metodología, 5. Desarrollo de las herramientas, 6. Primeros resultados y conclusiones. Referencias.

\title{
1. Justificación y antecedentes
}

Bajo las directrices marcadas por la Declaración de Bolonia (Gobierno de España; Unión Europea. 1999), el Comunicado de Praga (Gobierno de España; Unión Europea, 2001) y ante la implantación del Espacio Europeo de Educación Superior, en adelante EEES, las enseñanzas universitarias en Bellas Artes se enfrentan a unas interesantes posibilidades de mejora y perfeccionamiento, pero no exentas de multitud de complicaciones y riesgos inherentes al cambio de modelo educativo.

La implantación del EEES en la universidad española no está resultando como habría cabido esperar y nos encontramos ante la posibilidad real de un rotundo fracaso del nuevo modelo. Muchos son los problemas que han surgido en la mayoría de las universidades a la hora de abordar el nuevo paradigma educativo, pero cabe destacar, sin ningún género de dudas, que el mayor de los escoyos con los que se ha encontrado el proceso de convergencia es la gravísima crisis económica en la que estamos inmersos. Implantar un modelo que persigue la excelencia universitaria, la movilidad y una nueva relación entre el docente y el discente en tan pésimas condiciones económicas está, a nuestro entender, abocándonos al fracaso del EEES.

En el nuevo marco pedagógico planteado se apuesta por métodos formativos orientados a vencer dificultades, frente a los métodos informativos orientadosexclusivamente a transmitir conocimientos. Esta renovación metodológica tiene entre sus principales protagonistas al profesor, que ha de modificar su rol, en particular en lo referente a su relación con el alumnado. Como parte de la evolución de las metodologías docentes las Tecnologías de la Información y la Comunicación, las TIC, han traído nuevas formas de comunicación, aprendizaje y creación artística que amplían los modos tradicionales de recepción y transmisión de conocimientos.

En un modelo de universidad insertado en la sociedad global de la información, las TIC son un instrumento decisivo como soporte a la docencia, a la investigación y a la transferencia de conocimientos. Se plantean asimismo retos a afrontar como el desarrollo de nuevos programas docentes, el control de la calidad de los materiales y servicios virtuales o las buenas prácticas docentes en el uso de las mismas. 
La posibilidad de acceder a una gran cantidad de información facilita que el profesor abandone su actividad transmisora de conocimientos y focalice sus esfuerzos en el aprendizaje. La docencia se dirige entonces a desencadenar procesos de enseñanza con la finalidad de orientar al estudiante hacia la creación de su propio conocimiento a partir del conjunto de recursos de información disponibles. Al aumento de la autonomía del alumno que esto supone, se añade la superación de los condicionantes espaciales y temporales, la existencia de un gran potencial de interacción y la posibilidad de compartir el control de las actividades gracias a la comunicación en un marco de colaboración.

Entre las potencialidades que las TIC aportan a la enseñanza universitaria, podemos citar el elevado grado de personalización, la facilidad de interacción entre profesores y alumnos, la creación de nuevos canales de comunicación entre los discentes, la accesibilidad a un gran volumen de información de forma rápida y con un reducido coste, el aumento de la oferta educativa y la facilitación de la formación no presencial y, en consecuencia, de la formación permanente y a lo largo de toda la vida.

Entre los años 2005 y 2009, ante la implantación del EEES en la universidad española, las Facultades de Bellas Artes del Estado prepararon, según las directrices marcadas por las distintas comunidades autónomas, diferentes planes de estudio de Grado, con soluciones muy variadas y dispares en los itinerarios curriculares y más particularmente en lo que a la enseñanza de la fotografía se refiere tal y como veremos más adelante.

Con el EEES los distintos centros de enseñanza universitaria nos encontrábamos ante la oportunidad y el tremendo reto de realizar un buen itinerario en el que el alumno adquiriese todas las competencias y destrezas necesarias para poder enfrentarse con las suficientes garantías al mundo laboral y el mercado del arte a partir de su propia creación plástica.

El presente artículo pretende mostrar los resultados obtenidos, hasta el curso 2012/2013, tras la implantación del proyecto de innovación docente titulado El uso de las TIC aplicadas al aprendizaje autónomo del alumno en la enseñanza universitaria de fotografia. Elaboración de un aula didáctica virtual para la asignatura y estudio de resultados de mejora en la adquisición de habilidades y competencias, desarrollado en la asignatura Dibujo con Luz. Fotografía, perteneciente al Grado en Bellas Artes de la Universidad de Murcia.

Para alcanzar una mejor y más clara comprensión de las herramientas utilizadas en la realización de este proyecto así como la filosofía en la que se basan, consideramos imprescindible hacer un rápido repaso sobre el Movimiento Open, el proyecto Open Course Ware y las licencias Creative Commons.

\section{Filosofías y herramientas empleadas para una mayor difusión y accesibilidad de los contenidos educativos}

Con la aparición y consolidación en nuestra sociedad del World Wide Web y, especialmente, desde la democratización de los contenidos y la implicación del usuario como creador de los mismos que supuso la Web 2.0, las maneras de relacionarse e interactuar socialmente han experimentado un asombroso cambio.

Hacemos nuestras las reflexiones de Ariño, quien señala que el movimiento Open “desafía las vías de apropiación comercial privada, rechaza la reducción del conocimiento a mercancía o bien privado y reclama la construcción de un dominio público para el 
desarrollo de una cultura libre mediante la accesibilidad abierta" (Ariño, 2009, p. 11) y lo divide en tres grandes vertientes que lo conforman: Open Source Software, Open Access y Open Educational Resources.

\section{Open Source Software (OSS)}

Hace referencia al código abierto en el software de los ordenadores. Desde la década de los 80 el código fuente con el que se programaban las distintas aplicaciones se convirtió en algo cerrado y oculto al público. Ante este cambio de mentalidad en lo que antes de los ochenta era un código abierto y gratuito, surgen distintas iniciativas que buscan la propagación del software libre de código abierto, entre las que cabe destacar la iniciada en 1991 por Linus Torvalds con la creación, mediante un proyecto colaborativo, de un sistema operativo abierto: el sistema Linux.

\section{Open Access (OA)}

Es el término con el que nos referimos al acceso permanente, libre y online a resultados de investigación y producción científica generados por instituciones, comunidad universitaria, fundaciones, etcétera. La idea, es que con un simple acceso a internet, todo aquel que lo desee pueda consultar, extractar, citar, utilizar e incluso completar la información científica incluida en textos. El OA persigue la difusión de la creación científica así como los datos y protocolos que la han generado. La definición del OA que establece la Declaración de Berlín (2003) se refiere al mismo como "una fuente comprehensiva del conocimiento humano y del patrimonio cultural que ha sido aprobada por la comunidad científica" (Ariño 2009, p. 28). Ya que la investigación se nutre cada día más del trabajo colaborativo de grupos de investigación interconectados entre sí a través de la red y dado el creciente aumento exponencial de la producción científica y por lo tanto la necesidad de difusión de los resultados, la aparición del OA, el uso cada vez más habitual de ediciones electrónicas abiertas en revistas de investigación y otras muchas iniciativas surgidas bajo esta filosofia, proporcionan a los investigadores y al público general, un acceso universal a una cantidad ingente de recursos/resultados de investigación.

\section{Open Educational Resources (OER)}

Engloba muchas iniciativas educativas de acceso abierto. La UNESCO hace una definición del término refiriéndose a él como la difusión y puesta a disposición de manera abierta y gratuita de recursos educativos, apoyándose en las posibilidades que ofrecen las TIC para su uso y consulta por cualquier usuario con fines no comerciales (Geser, 2007). El OER es por tanto cualquier repositorio online enfocado a la enseñanza incluyendo en esta estrategia cursos completos, libros de texto, imágenes, artículos, videos, objetos de aprendizaje, audios, software y cualquier otro material que pueda ser utilizado como soporte para el aprendizaje.

\section{Open Course Ware (OCW)}

Siendo probablemente una de las iniciativas más interesantes y de mayor difusión surgidas al amparo de los OER nos encontramos el proyecto Open Course Ware $(\mathrm{OCW})$. Esta iniciativa nace a instancias de la Fundación William and Flora Hewlett, la Fundación Andrew W. Mellon y el Instituto Tecnológico de Massachusetts (MIT) en el año 1999, con el objetivo de poner a disposición del público mediante un acceso libre, sencillo y coherente, cursos completos y en distintos idiomas, de las materias impartidas en las universidades adscritas. Para canalizar todas las instituciones se creó el 
Open Course Ware Consortium (http://www.ocwconsortium.org, consulta 10/12/2013) un consorcio que organiza por regiones todas las iniciativas OCW. En febrero de 2014 se hallaban adheridas a este proyecto 258 instituciones de todo el mundo, 35 de ellas españolas, entre las que se encuentra la Universidad de Murcia con su portal (http://ocw. um.es, consulta 01/02/2014)

Entre las ventajas que aporta el proyecto cabe destacar la liberalización de recursos didácticos, la innovación y perfeccionamiento de los recursos docentes usados por los profesores, el acercamiento a las TIC por parte de docentes y discentes, así como su flexibilidad y repercusión a nivel global.

En el marco del OER y muy utilizado en el OCW nos encontramos ante el concepto de los llamados "objetos de aprendizaje" que podemos denominar como "cualquier recurso digital que pueda ser reutilizado para proporcionar apoyo al aprendizaje" (Wiley, 2000, p. 7). Al igual que otras instituciones, la Universidad de Murcia, en adelante UM, ha creado servicios y ayudas para producir, divulgar y gestionar estos objetos. Tal es el caso de la Unidad para la Innovación, que junto con Unidad de apoyo Multimedia de la UM gestiona los "objetos didácticos" (OD), que es cómo nuestra institución ha denominado a los "objetos de aprendizaje".

\section{Las licencias Creative Commons (CC)}

El desarrollo de las distintas iniciativas Open así como el auge y ubicuidad de la Web 2.0 en nuestra cotidianeidad, plantea múltiples problemas y desafíos a la hora de gestionar y aplicar los derechos de autoría (Ariño, 2009). Mucho se ha hablado de este tema y las distintas legislaciones nacionales y comunitarias, buscan dar una tardía respuesta a una problemática que evoluciona a mayor velocidad de lo que lo hacen las leyes. Si el movimiento Open persigue la liberalización y democratización de la cultura a través de la digitalización global de los contenidos, se hace necesario reformular el antiguo sistema del copyright, basado en una sociedad predigital y a nuestro juicio abocado irremediablemente a la extinción.

Con el objetivo de dar respuesta a estas necesidades surgen en 2002 las licencias Creative Commons (Lessing, 2005, p. 279) que han sido aplicadas por la mayoría de proyectos Open, entre ellos el OCW. Las Creative Commons no anulan las licencias de Copyright, sino que las matizan y actualizan a los nuevos y asombrosos cambios sociales.

Las obras o contenidos generados bajo licencia CC ceden derechos a los usuarios, bajo ciertas condiciones que se engloban en seis tipos de licencia:

- Atribución: El material puede ser distribuido, copiado y mostrado por terceros siempre que se reconozca la autoría.

- Atribución sin obra derivada: El material puede ser distribuido, copiado y mostrado por terceros siempre que se reconozca la autoría. Además, no puede generar obras derivadas.

- Atribución sin obra derivada - No comercial: El material puede ser distribuido, copiado y mostrado por terceros siempre que se reconozca la autoría. Además, no puede generar obras derivadas ni se puede obtener de ellas beneficio comercial.

- Atribución no comercial: El material puede ser distribuido, copiado y mostrado por terceros siempre que se reconozca la autoría. No se puede obtener de ellas beneficio comercial. 
- Atribución no comercial por igual: El material puede ser distribuido, copiado y mostrado por terceros siempre que se reconozca la autoría. No se puede obtener de ellas beneficio comercial y las obras derivadas han de estar bajo la misma licencia que el original. Esta licencia es la escogida por el consorcio OCW al que pertenece la Universidad de Murcia para compartir sus contenidos.

- Atribución por igual: El material puede ser distribuido, copiado y mostrado por terceros siempre que se reconozca la autoría. Las obras derivadas han de estar bajo la misma licencia que el original (http://creativecommons.org/licenses, consulta 05/02/2014).

\section{Presentación del proyecto}

Tanto en los actuales planes de Grado regulados con la LOMLOU (Ley Orgánica 4/2007, de 12 de abril, por la que se modifica la Ley Orgánica 6/2001, de 21 de diciembre, de Universidades) (Gobierno de España, 2007) como en las anteriores enseñanzas universitarias basadas en la LOU (Ley Orgánica 6/2001, de 21 de diciembre, de Universidades) (Gobierno de España, 2001) la docencia en fotografía suele articularse en dos cursos, tres en el mejor de los casos. El primer curso, que tiende a llamarse Fotografía I, Fotografia básica o Fundamentos de la fotografia, se centra en los fundamentos básicos de la imagen, el lenguaje, la composición, la técnica, etcétera. Su objetivo es preparar al alumno con unos conocimientos técnicos esenciales que le permitan generar y desarrollar un lenguaje fotográfico propio en el segundo curso. En la actualidad la mayoría de facultades del estado español incluyen en las guías docentes de primer curso el conocimiento y manejo de las técnicas digitales.

En un segundo curso, que se acostumbra a llamar, Fotografia II, Aplicaciones fotográficas o lenguajes y procesos fotográficos, se enfoca a un conocimiento más profundo de técnicas y materiales que va desde el trabajo de laboratorio/medialab y plató avanzado, al uso de cámaras técnicas. También es común en este curso comenzar a dar voz al lenguaje personal de cada alumno explotando sus virtudes, limando defectos y planteando proyectos.

En un tercer curso, Proyectos fotográficos, Producción artística. Fotografia o Idea y Concepto fotográfico, el alumno ha adquirido la habilidad de dominar la técnica fotográfica y se persigue el desarrollo y perfeccionamiento artístico del lenguaje, investigando mensajes y planteamientos bajo la tutela del profesor, cuya función se torna más en la de un director de arte. El conocimiento de las tendencias del mercado, los nuevos planteamientos visuales, así como el desarrollo de proyectos más ambiciosos y arriesgados tienen cabida en esta asignatura que en algunos planes de estudio se encuentra en Tercer Ciclo en los Másteres Oficiales que la mayoría de centros ofrecen.

En ocasiones, a estos tres cursos se le suma alguna otra asignatura, optativa generalmente, enfocada al uso y las técnicas de la fotografía digital (cuando este tema no se ha abordado en los temarios de las asignaturas anteriores). Estas optativas han sido ofrecidas por muchos centros como medida de actualización ante el avance de los soportes digitales y la práctica extinción a nivel profesional de la fotografía argéntica.

La adaptación curricular de los planes de Grado no ha sido todo lo adecuada o deseable que hubiera cabido esperar, especialmente en el caso más clamorosamente 
obsoleto, el de la Fotografía básica. Se trata de aquellos temarios que, aún hoy, basan gran parte de la enseñanza en unas técnicas que nuestros alumnos apenas van a poder utilizar cuando abandonen las aulas, con equipos que ya sólo se encuentran en las tiendas de segunda mano y para un mercado que se ha renovado y reinventado. Bien es cierto que, poco a poco, la mayoría de los centros incluyen en las guías docentes de primer curso el conocimiento y manejo de las técnicas digitales.

Nuestro objetivo como docentes es preparar al alumno para dominar no sólo la sintaxis de la fotografía, sino las técnicas que pueda llegar a necesitar y que le ayuden a avanzar en su trabajo. Ojalá pudiéramos decir que nuestros estudiantes vivirán de su propia obra sin responder ante un director de arte, un editor o un cliente, pero la inmensa mayoría de los que se dediquen a la fotografía profesionalmente lo harán trabajando por cuenta ajena, en prensa, cine, publicidad, etcétera. Sólo unos pocos podrán permitirse trabajar una cianotipia, un calotipo o positivar manualmente una imagen. Para el resto, conceptos como el coste, el envío de imágenes vía internet, la instantaneidad y el binomio resultados/tiempo serán fundamentales. Las asignaturas que impartimos disponen de poco tiempo y desperdiciamos unas preciosas horas enseñando fotografía con máquinas de vapor que, aún siendo maravillosas, no dejan de ser algo del pasado.

Ante los retos planteados por la implementación del Grado en Bellas Artes en la UM, surge en 2009 la necesidad de desarrollar el proyecto de innovación docente que nos ocupa, a raíz de las primeras experiencias docentes con el uso de los "objetos didácticos" (OD) en el aprendizaje autónomo del alumno. La asignatura objeto de la investigación será Dibujo con luz. Fotografía, que encontramos localizada administrativamente en primer curso, dentro de la Materia Leguajes y soportes de la imagen de la titulación de Grado en Bellas Artes, adscrita al Departamento de Bellas Artes de la Universidad de Murcia.

La hipótesis de partida es que el desarrollo avanzado de estas herramientas y cualquier otro recurso que las TIC proporcionen en la enseñanza universitaria de la fotografía puede aportar sustanciales mejoras en la adquisición de competencias y habilidades. Las TIC podrían suplir así la drástica reducción de horas presenciales, así como presupuestaria, que ha sufrido la materia, fomentando el autoaprendizaje por parte de los discentes como estrategia del nuevo modelo de enseñanza fomentado por el EEES.

Entre los objetivos generales del proyecto podemos encontrar:

- Desarrollar un entorno virtual y todos los contenidos necesarios, tanto teóricos, como prácticos, que sirva como apoyo a la docencia de la enseñanza básica de la fotografía en entornos universitarios de habla hispana, tomando como modelo la asignatura Dibujo con luz. Fotografia impartida en la UM.

- Facilitar el trabajo autónomo del alumno, fomentando la resolución de problemas, el aprendizaje cooperativo y la auto evaluación tal y como plantean los objetivos del EEES.

- Demostrar la utilidad docente de las TIC en la enseñanza de las Bellas Artes y de la materia en cuestión, mediante la evaluación de los resultados obtenidos en la Universidad de Murcia, la Universidad Nacional de La Plata y la Universidad Complutense de Madrid, tras el periodo de investigación. 
De manera más específica los objetivos se centran en:

- Ofrecer a través del entorno virtual, recursos variados para facilitar la comprensión del contenido teórico-práctico de la materia, generando el material didáctico necesario para un aprendizaje autónomo de las prácticas de la asignatura. Este material consistirá en Foros, OD, Wikis, redes sociales, tutoriales, herramientas de autoevaluación, ejercicios, etcétera.

- Poner estos contenidos a disposición de cualquier alumno de la universitario interesado en la materia, haciéndolos accesibles desde la red mediante licencia Creative Commons 4.0 e integrarlo en el proyecto $\mathrm{OCW}$.

- Facilitar a los alumnos extranjeros o de intercambio la comprensión de estos contenidos mediante la traducción de los mismos al inglés y francés.

- Generar, un manual de la materia, online e interactivo, a disposición de los discentes en el que puedan encontrar todo el contenido de la misma así como los contenidos digitales generados.

- Desarrollar visitas académicas a distintos centros universitarios, tanto nacionales como extranjeros, con el fin de estudiar las distintas posibilidades de implantación y adaptación del proyecto, teniendo en cuenta las distintas metodologías de enseñanza y programaciones didácticas

- Implantar este nuevo entorno virtual con todos los contenidos que se plantean y desarrollar un estudio de la evolución del alumnado, el uso que se hace de los recursos puestos a su disposición así como los resultados obtenidos en la materia.

El proyecto de innovación docente que nos ocupa inicia su fase de pruebas en el curso 2009/10, con el apoyo de la Universidad de Murcia y bajo el amparo de la iniciativa OCW. Con muy poco material de inicio y añadiendo cada año más recursos (OD, traducción de prácticas al inglés, herramientas de autoevaluación, etcétera) podemos afirmar que los resultados arrojados son tremendamente satisfactorios tal y como muestran los datos que más adelante analizaremos.

El proyecto se encuentra a día de hoy en su ecuador y las estadísticas que arroja la asignatura de Dibujo con Luz. Fotografia son sensiblemente mejores cada curso académico. En líneas generales y sin entrar por el momento en detalles, los datos aportados por la Universidad de Murcia y el servicio ATICA demuestran que la tasa de aprobados de la asignatura ha aumentado un $15 \%$ en el periodo que va del curso 2009/10 al 2012/13. Así mismo, el uso del Aula Virtual y las herramientas de enseñanza multimedia por parte de los alumnos de la materia, ha aumentado en el curso 2012/13 un $342 \%$, respecto al curso 2009/10 siendo en la actualidad la materia con el mayor tráfico de usuarios de toda la titulación y una de las de mayor tráfico de toda la Universidad de Murcia.

Creemos que los resultados que está aportando la implantación del Aula virtual para la enseñanza de fotografía y las herramientas que la componen nos muestran los beneficios del proyecto así como lo acertado del camino emprendido. La culminación de los objetivos del proyecto durante los próximos cursos proporcionará tanto a docentes como discentes una aplicación de gran potencial para la adquisición de competencias relacionadas con la materia. 


\section{Metodología}

La metodología a emplear durante la realización de la investigación se orientará hacia un estudio aplicado, teniendo como propósito primordial la resolución de problemas en pos de una mejora de la calidad de la enseñanza virtual y el desarrollo autónomo de competencias por parte del alumno.

El presente proyecto se enmarca dentro del ámbito educativo, por lo que el modelo de investigación escogido es el interpretativo, descriptivo y de campo, que nos proporcionará una propuesta de aplicación de las TIC en el ámbito educativo de las Bellas Artes y la enseñanza universitaria de la fotografía.

La investigación de carácter descriptivo pretende medir los resultados obtenidos para luego interpretar sistemáticamente las características del fenómeno estudiado en base a la realidad del escenario planteado. "La investigación descriptiva trabaja sobre las realidades de los hechos y sus características fundamentales es de presentarnos una interpretación correcta" (Tamayo, 1999, p. 54).

En un primer momento, nuestro objetivo será el de diagnosticar las necesidades propias de los discentes en lo referente a la enseñanza virtual y el uso de las TIC para así poder diseñar un entorno virtual, interactivo y versátil nutrido con herramientas óptimas para su buen funcionamiento.

Para comprobar la viabilidad de las soluciones aportadas en torno al objeto de investigación se desarrollará una recogida sistemática de datos pertenecientes tanto al entorno físico del aula como al virtual, y correspondientes a un periodo de dos cursos académicos. Algunos ejemplos del tipo de información reunida son: las encuestas, los diagramas de flujo y de uso del entorno virtual, los informes del profesorado acerca de la adquisición de competencias y los resultados obtenidos por los discentes desde la implantación de la herramienta. El análisis y estudio de dicha información tendrá como objeto la elaboración de una serie de conclusiones y de recomendaciones pertinentes. 


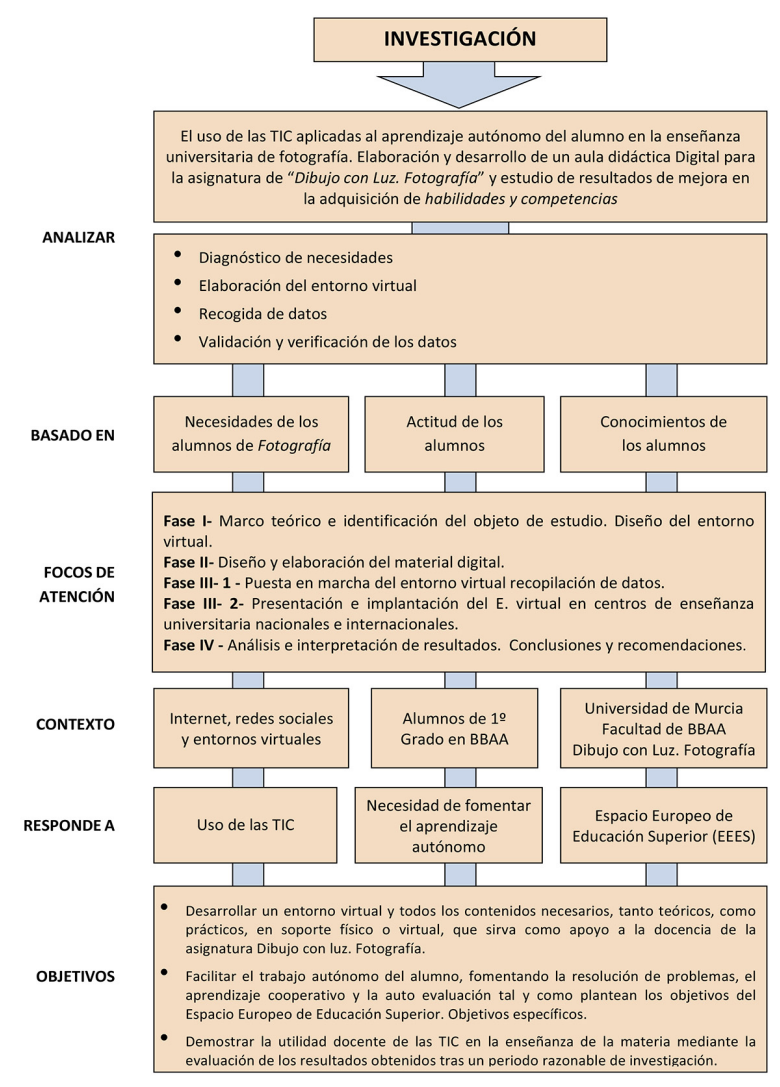

Figura 1. Esquema de la metodología utilizada (Cuadro de elaboración propia).

\section{Desarrollo de las herramientas}

La Universidad de Murcia viene trabajando desde hace una década a través de distintos vicerrectorados y desde 2010 a través de la Unidad de Innovación, en distintas plataformas de apoyo a la enseñanza virtual. Si bien algunas no son de contenido abierto, la apuesta de la institución por este tipo de contenidos se hace patente en la constante implementación de nuevos espacios, como pueda ser la participación en Miríada-X, una iniciativa de Universia orientada a promover los cursos en red masivos y abiertos (Massive Online Open Course - MOOC). Los MOOCs son un ejemplo de formación a distancia planificados para alcanzar un elevado volumen de usuarios gracias a su carácter abierto, participativo y gratuito.

\section{El Aula Virtual}

Como otras muchas instituciones académicas, la Universidad de Murcia posee un campus virtual de apoyo a la enseñanza. En el caso de la UM el Aula Virtual, en adelante $\mathrm{AV}$, es el espacio en el cual los profesores y alumnos podrán encontrar diversas herramientas telemáticas que facilitarán el desarrollo de los procesos de enseñanza y aprendizaje, así como herramientas que, de forma general, permitirán una comunicación 
más flexible y el acceso a información y recursos digitales de asignaturas de todas las enseñanzas ofertadas por la Universidad de Murcia (tanto formación reglada: grados, posgrados, y titulaciones a extinguir como formación no reglada: cursos de estudios propios, etcétera).

Bajo la filosofía y directrices marcadas por la Declaración de Bolonia y el Comunicado de Praga en lo que al uso de las TIC se refiere, el aprendizaje autónomo del alumno y el cambio de metodología docente hacia un alumnado más activo y partícipe de su propio aprendizaje, la UMU implantó en el año 1998 la primera versión de su Campus Virtual, a la que llamó SUMA (Servicios de la Universidad de Murcia Abierta). Con ella se pretendía integrar en una única plataforma aplicaciones docentes y de gestión acercando así la Universidad a los diferentes miembros de la misma. Aquella primera versión de SUMA puso a disposición de profesores y alumnos una serie de herramientas telemáticas que sin duda mejoraron el aprendizaje y posibilitaron un acceso universal a en cualquier momento y desde cualquier lugar al centro docente. En el año 2009 la herramienta es actualizada a SUMA 2.0 y ante el potencial demostrado y las posibilidades de la Web 2.0 es sustituida, en su módulo Docente, por el Aula Virtual, en septiembre de 2010 basada en la plataforma eLearning de software libre SAKAI.

El acceso al AV de la UM es, independientemente del rol que se posea, mediante usuario y clave de acceso, lo que otorga al docente y a la propia institución un control sobre la identidad de los usuarios y el acceso a las distintas herramientas. Este aspecto nos proporcionará, unas estadísticas de uso generales y específicas de gran precisión y fiabilidad, algo que como veremos, cobra relevancia a la hora de interpretar los resultados.

Tanto el docente como el discente puede encontrar en el AV de la UM el acceso a todos los portales de cada asignatura que imparten o en la que están matriculados, con herramientas tan interesantes como los foros, exámenes, tutorías electrónicas, chats grupales, video conferencias, recursos de la asignatura, listas de espera o información general de la materia, wikis, estadísticas, calificaciones, anuncios, Url recomendadas, blogs y un largo etcétera.

En el entorno dado por el AV los docentes en fotografía tomamos la decisión de desarrollar especialmente algunas de estas herramientas, que a continuación desglosamos en el orden en el que fueron implementadas, en aras de alcanzar los objetivos marcados por el proyecto:

A. La Guía Docente. Ésta es un contrato establecido entre la universidad, representada por el departamento en la figura de los docentes, y los alumnos que cursan la asignatura abonando una matrícula que, con el transcurso de los años, es cada día más cara. Consideramos que la difusión de la guía docente no sólo es una obligación, sino un recurso de vital importancia en el correcto funcionamiento de una asignatura.

Para favorecer el acceso de todos los discentes a dicha información el primer paso que nos planteamos fue la publicación en distintos formatos e idiomas (castellano, inglés y francés) del documento, así como una revisión de la evaluación de la asignatura, en la que incluimos como un ítem a puntuar, el uso y participación en el AV, los foros y las distintas herramientas que la componen (https://aulavirtual.um.es/umugdocente-tool/htmlprint/ guia/R0D4GHHCtzI8PM0BpV6utxL36uweoMs1LsRGlxjMCAuWZwgGTE9, consulta 10/09/2014). 
B. Los recursos. Esta herramienta no deja de ser un disco duro virtual en el que los docentes pueden subir distintos materiales relacionados con la asignatura. En el caso de Dibujo con luz. Fotografia los alumnos tienen acceso a todas las clases que se van a impartir en formato PDF, así como a las fichas de cada actividad dirigida durante el curso, ejemplos de las mismas realizados por sus compañeros de cursos anteriores, artículos, documentos legales, etcétera. El equipo que integra este proyecto ha hecho un especial esfuerzo para que todo el material sea común, independientemente del grupo en el que el alumno curse la asignatura, y esté disponible desde el comienzo del curso. Cualquier alumno puede por tanto recuperar una clase a la que no haya podido asistir o simplemente para reforzar los conocimientos adquiridos. Durante el curso 2012/13 se realizaron 27862 entradas de visitantes únicos, lo que supone un incremento del 93\% respecto al curso 2011/12 con 14429 entradas.

En el estado actual del proyecto las clases no están locutadas, pero es la intención de este equipo realizar una locución de todas y cada una de las clases impartidas y subidas al AV a lo largo del próximo año. Tal y como veremos en los datos estadísticos, hay una relación directa en el número de recursos consultados y bajados por los alumnos y los resultados obtenidos, por lo que consideramos fundamental continuar enriqueciendo esta herramienta.

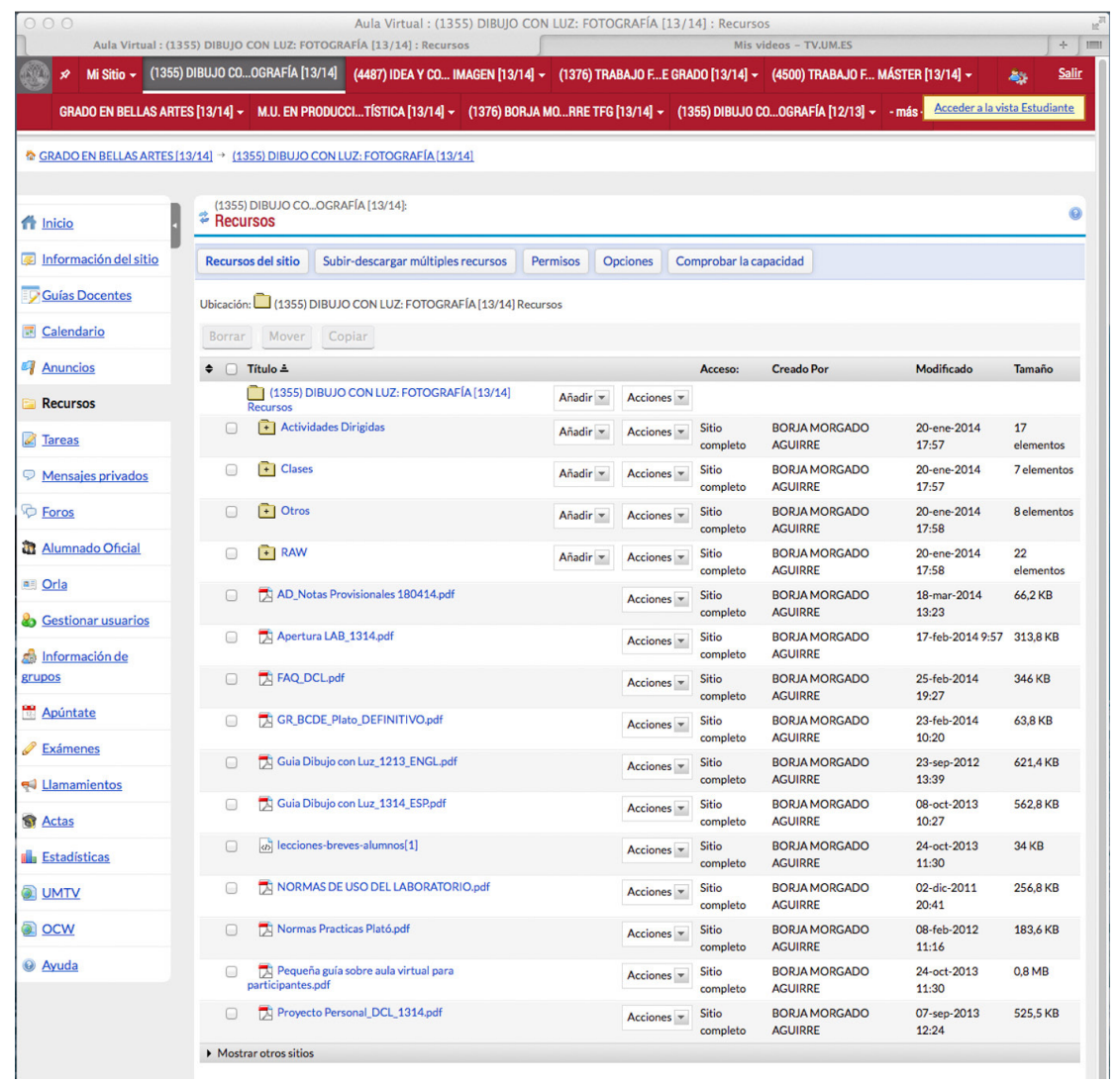

Figura 2. Aula Virtual de la Universidad de Murcia.1355: Dibujo con luz. Fotografía. Sección: recursos. 
C. Tutorías virtuales (mensajes privados). La tutoría es con mucho, una de las herramientas docentes de mayor transcendencia para los profesores, siendo el caso de las Bellas Artes un área en la que este recurso cobra especial relevancia.

Consideramos más interesante y útil para el desarrollo de esta asignatura las tutorías presenciales por lo que mantenemos el carácter presencial de las mismas. No obstante, la herramienta de tutoría virtual supone despejar innumerables dudas superfluas, técnicas y de procedimiento a través del $\mathrm{AV}$, dejando cuestiones más trascendentes para las tutorías presenciales, que han ganado en tiempo y calidad de los resultados.

Las 6047 tutorías virtuales en el curso 2012/13 han supuesto un aprovechamiento del tiempo y mejora de los resultados, así como un aumento del $182 \%$ en el número de tutorías virtuales del periodo 2011/12, lo que ha facilitado el trabajo realizado por los docentes en las más de 350 tutorías presenciales del mismo periodo.

D. Anuncios. Esta herramienta, que sustituye a los antiguos tablones de anuncios o vitrinas, es de uso exclusivo para los docentes, y posibilita un flujo de información unidireccional puntual, actualizada y detallada sobre exposiciones, convocatorias, prácticas, talleres y cualquier otra cosa que tenga que ver con la materia. Su repercusión en los resultados de la asignatura no es directa, si bien redirecciona a los discentes hacia otras áreas más participativas.

E. Tareas. La entrega periódica de actividades académicas dirigidas es una pieza clave para el trabajo constante y la evaluación continua de las competencias de los alumnos. Al finalizar cada unidad didáctica se publican mediante esta herramienta las actividades a realizar, la fecha de entrega de las mismas, así como los ejemplos de actividades realizadas por alumnos de cursos precedentes. La entrega de los trabajos por parte de los estudiantes se hace de manera virtual, pudiendo el profesorado descargarse todos los ejercicios, evaluarlos y publicar las calificaciones también virtualmente. A posteriori se establecen clases grupales o tutorías presenciales en las que se analizan los ejercicios resultados.

A lo largo del último curso estudiado se realizaron 1390 entregas de actividades dirigidas a través de la herramienta Tareas. Contrastándolas con las 251 entregas del curso $2011 / 12$ y las 185 del $2010 / 11$ supone un incremento del $453 \%$ y el $1057 \%$ respectivamente. 


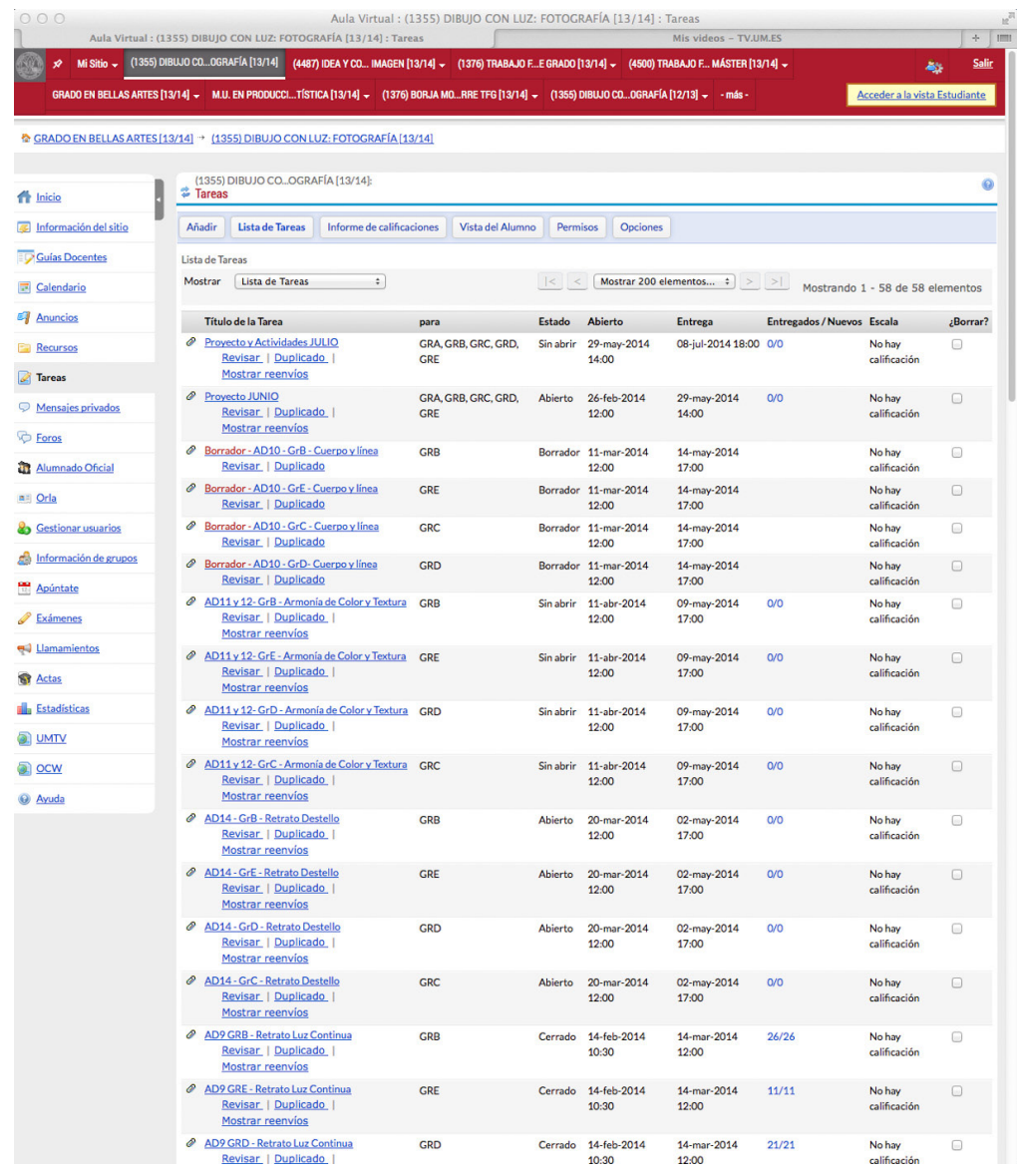

Figura 3. Aula Virtual. Sección: tareas.

E. Foros. La implantación de los foros tuvo lugar durante el curso 2011/12, pero hubo que esperar al periodo 2012/13 para poder obtener datos que cuantificasen el uso que le habían dado los alumnos, así como su participación en el AV. En esta herramienta participan únicamente los alumnos, que en una serie de canales temáticos plantean sus preguntas y dudas para que otros compañeros las respondan. La participación del profesorado es meramente moderadora y únicamente cuando, tras un periodo prudencial, se hace necesario guiar a los discentes en la resolución de un problema. El aprendizaje colaborativo y la resolución autónoma de problemas a través de esta herramienta refuerza uno de los pilares en los que se basa el EEES, que como sabemos, otorga al discente una gran responsabilidad en su aprendizaje. Al llevar tan sólo un curso en funcionamiento los foros tienen aún mucho margen de mejora y potencial.

En el periodo 2011/12 el uso de los foros registró 739 entradas por las 19164 del curso 2012/13. En febrero del 2013 esta herramienta registraba 9350 entradas, mientras que en febrero de 2014 el sistema confirmaba 10184 entradas de usuarios únicos, lo que supone un incremento del $8 \%$. 


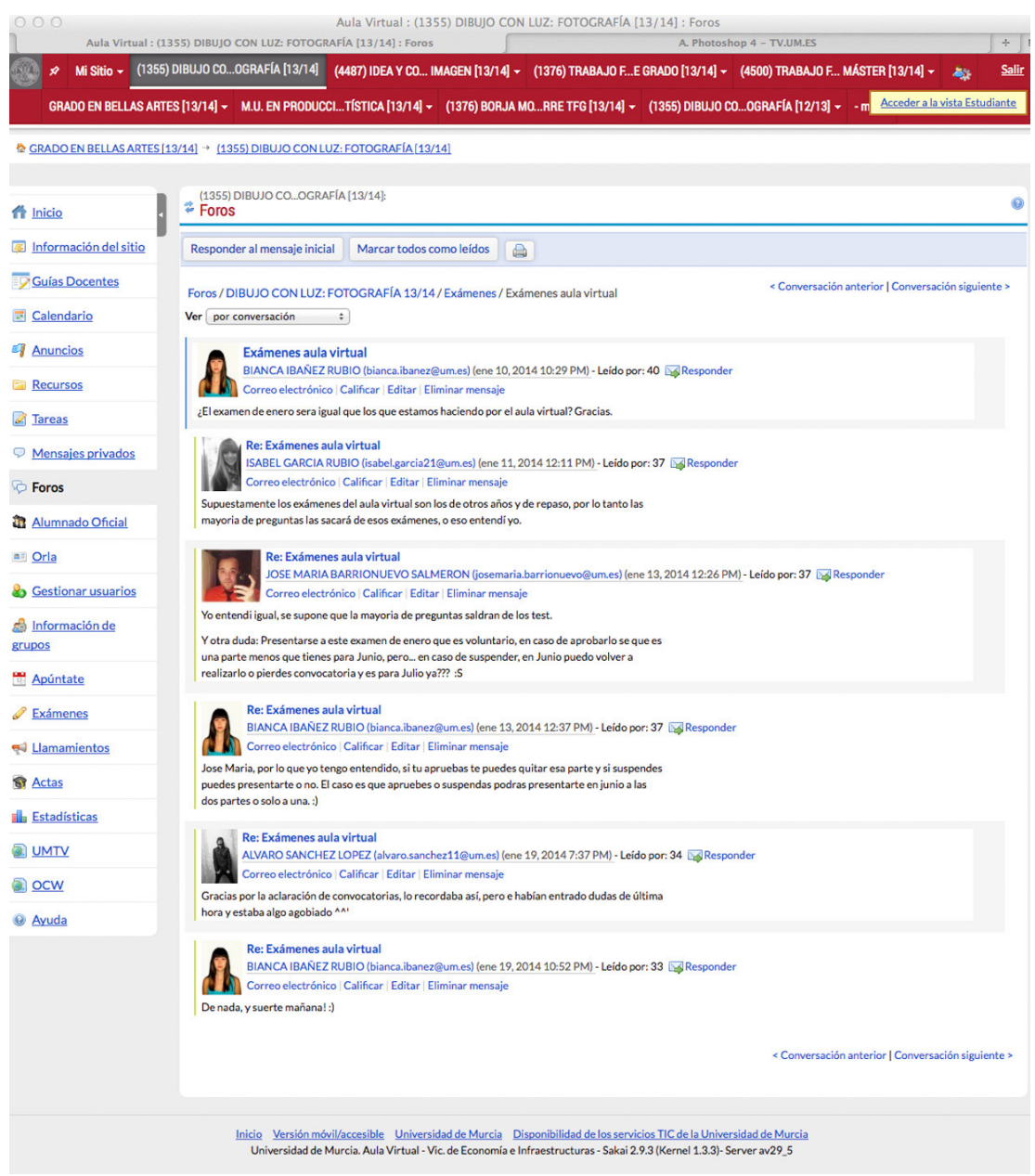

Figura 4. Aula Virtual. Sección: foros.

E. Exámenes. Se trata de una herramienta de reciente implantación pero que es implementada por la UM con otro objetivo. En principio el fin de esta herramienta es sustituir a las pruebas de conocimiento tradicionales y que la nota arrojada por la prueba sea automáticamente adjuntada a la herramienta calificaciones.

El equipo docente vio en esta aplicación una interesante herramienta de autoevaluación por parte de los alumnos y con tal objetivo se crearon cinco exámenes de autoevaluación, uno por cada bloque temático, que el alumno puede realizar cuantas veces considere necesario durante todo el curso. Dichas pruebas constan de veinticinco preguntas tipo test con una única respuesta correcta. Cada bloque se nutre de una batería de más de 200 preguntas de entre las que el programa selecciona de forma aleatoria veinticinco para cada examen haciendo muy difícil la generación de dos exámenes iguales.

$\mathrm{Al}$ terminar la prueba los alumnos pueden ver su calificación y los errores cometidos, consultando cualquier duda con los compañeros a través de los foros. La discusión de 
los resultados, la posibilidad de realizar innumerables pruebas de cada bloque y las múltiples preguntas de las baterías, han posibilitado una increíble tasa de mejora en los resultados del bloque técnico, que en esta asignatura generaba innumerables suspensos a los estudiantes.

Durante el curso 2012/13 se realizaron 9808 exámenes de autoevaluación y la tasa de aprobados en el apartado técnico de la asignatura aumentó un $4 \%$ respecto al curso anterior. En lo que llevamos de curso 2013/14, el incremento de actividad en esta herramienta está siendo del $6 \%$ lo que, de ser cierta la tendencia, desencadenaría una mejora en las notas medias de este apartado.

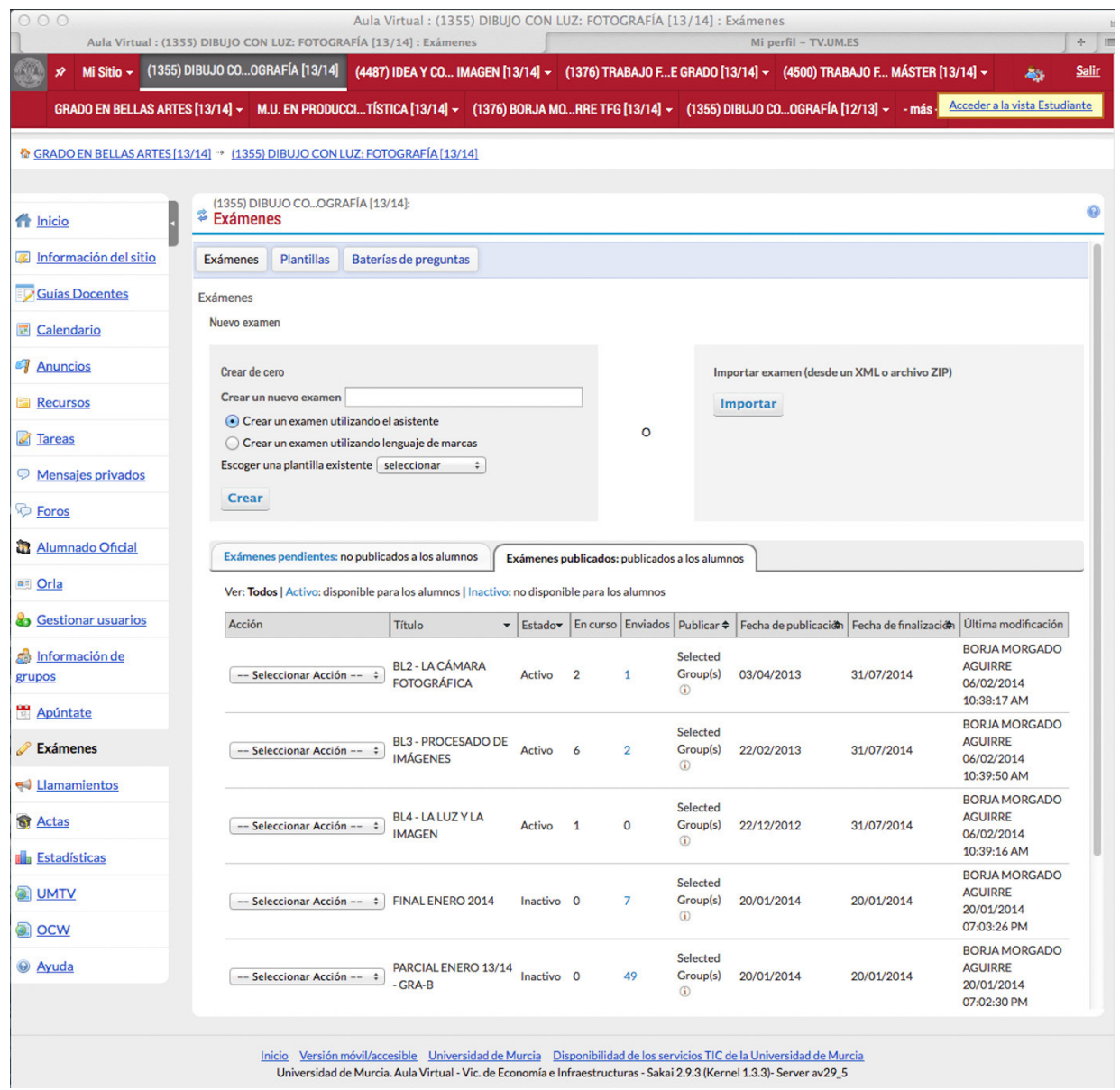

Figura. 5. Aula Virtual. Sección: exámenes. (Rol Docente. Captura de Pantalla)

\section{El espacio UMTV}

La universidad de Murcia tiene entre sus más interesantes herramientas de innovación docente el portal UMTV, un gigantesco espacio en el que la propia institución y los docentes que así lo deseen pueden subir los Objetos Didácticos de aprendizaje (OD) que estimen oportunos en formato video. 
Con una duración de entre 10 y 15 minutos el canal de Dibujo con luz. Fotografía (http://tv.um.es/videos? serie=4741, consulta 20/02/2014) cuenta en febrero de 2014 con más de 80 recursos que cubren todo el temario de la asignatura. Estas píldoras docentes con licencia Creative Commons pueden ser visualizadas y descargadas por todo aquel que lo desee, sea alumno o no de la UM. Cada video ha sido diseñado y grabado para ayudar al alumno de la asignatura a reforzar los conocimientos adquiridos o a adquirir aquellos que, según el criterio de los docentes, han de aprender de manera autónoma en su domicilio. Estas píldoras son sin ningún género de dudas la espina dorsal de este proyecto y se han ido implementando curso tras curso de manera global, teniendo en cuenta la transversalidad del temario, de lo general a lo particular.

Gracias a estos recursos se ha podido ganar una considerable cantidad de tiempo para talleres presenciales, salidas de campo con el profesor, prácticas y otras actividades que anteriormente no podían realizarse por falta de tiempo.

Al ser de acceso libre, no se pueden establecer estadísticas de uso fiables por parte de los alumnos de la asignatura, ya que no se puede discernir los visitantes que estudian la materia oficialmente de aquellos usuarios externos. No obstante, al existir una parte del temario que se imparte de manera virtual a través de esta herramienta, gracias a las encuestas realizadas al alumnado sobre su uso y contrastando los resultados académicos obtenidos en años anteriores con el aumento de los OD, podemos asegurar que su uso es masivo y su influencia en los resultados académicos notoria.
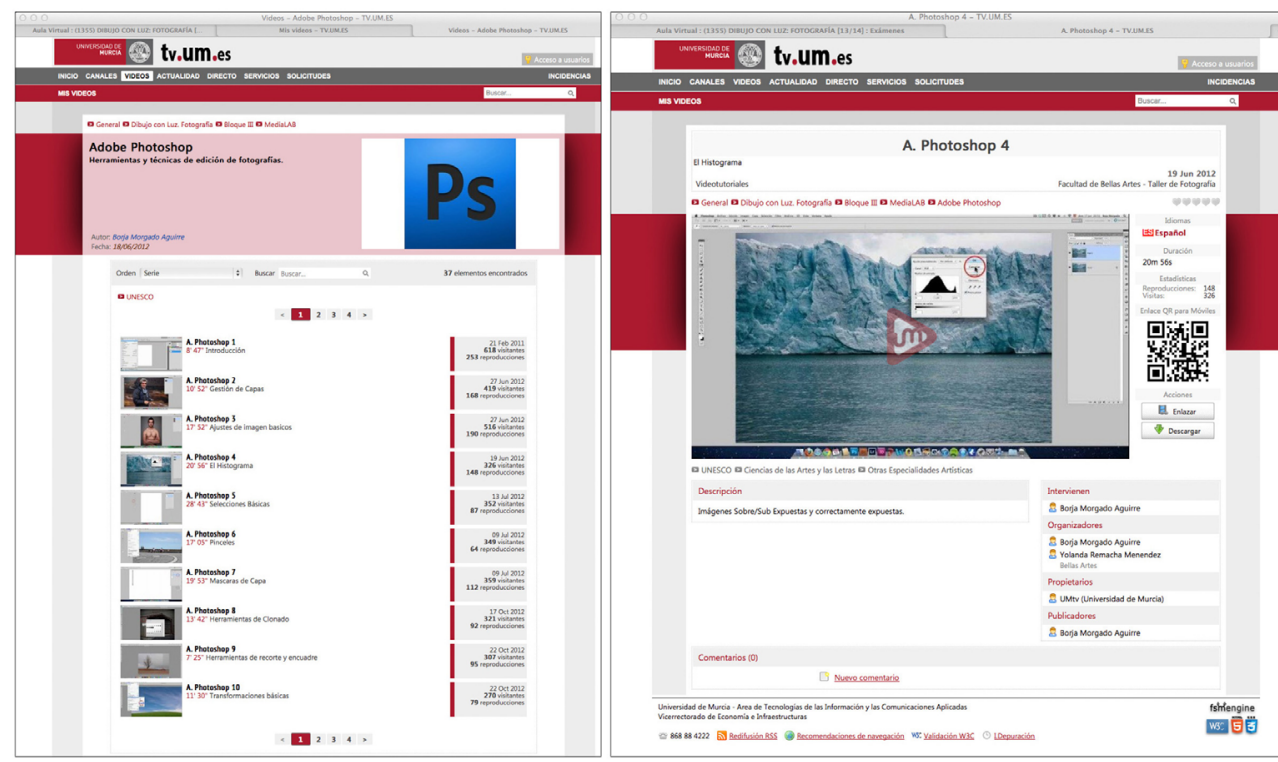

Figura 6A.Web UMTV. Canal de la asignatura Dibujo con luz. Fotografía. Captura de Pantalla del Bloque III:Medialab.

Figura 6B.Captura de Pantalla del OD. A. Photoshop 4: El Histograma. 


\section{El canal de Facebook de la asignatura.}

Como complemento a la formación autónoma del alumno el presente curso 2013/2014 se ha implementado una canal abierto de la asignatura en la red social Facebook, que en 2012 ya superaba los 900 millones de usuarios. Dado que la gran mayoría de los estudiantes es usuario habitual de esta plataforma el canal de la asignatura, llamado DCL-Murcia (https://www.facebook.com/pages/DCL-Murcia/546231472075555, consulta 10/06/2014), pretende aportar conocimientos extra sobre cursos, concursos, exposiciones, eventos o cualquier otra cosa que tenga que ver con la fotografía para todos aquellos alumnos que quieran ampliar su formación y tengan inquietud por el tema. Con 136 seguidores de la página, de los cuales 98 son de la zona de Murcia, Alicante y Cartagena, el portal recibe una media de 82 visitas diarias. Cabe destacar que al no tratarse de una herramienta reglada, con control de acceso y de un desarrollador externo, en éste portal no se ofrecen contenidos didácticos evaluables, sino que se trata únicamente de un portal informativo complementario a la docencia y de uso voluntario.

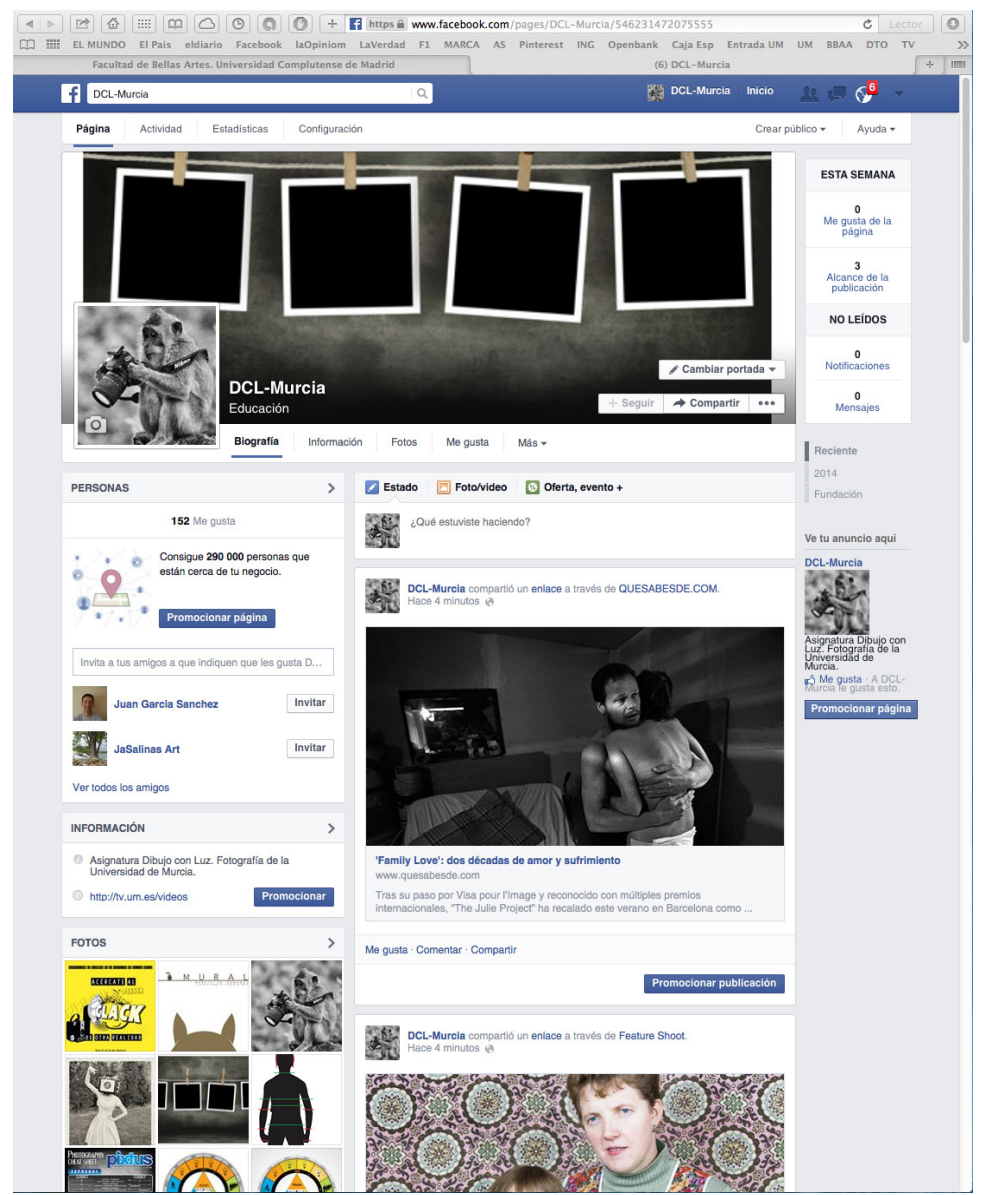

Figura 7.Canal Facebook de la asignatura. Captura de Pantalla. 


\section{El portal OCW de la asignatura.}

Como ya hemos comentado anteriormente la Universidad de Murcia se encuentra adherida al consorcio Open Course Ware a través de su portal OCW (http://ocw.um.es, consulta 10/05/2014), ) desde el año 2008. La iniciativa OCW pretende promover el acceso libre y gratuito a la información a través de la publicación abierta de recursos docentes en red, a disposición de cualquier interesado en ellos.

En febrero de 2014 todos los contenidos de la asignatura Dibujo con luz. Fotografía están disponibles a través del portal OCW de la misma (http://ocw.um.es/artes-1/dibujocon-luz.-fotografia, consulta 01/03/2014), siendo el objetivo de este equipo la difusión de los materiales y la utilización de este espacio como herramienta de apoyo para la implantación de la fase III del proyecto: estudiar la posible implantación del mismo en otras enseñanzas universitarias de la fotografía y analizar los resultados obtenidos.

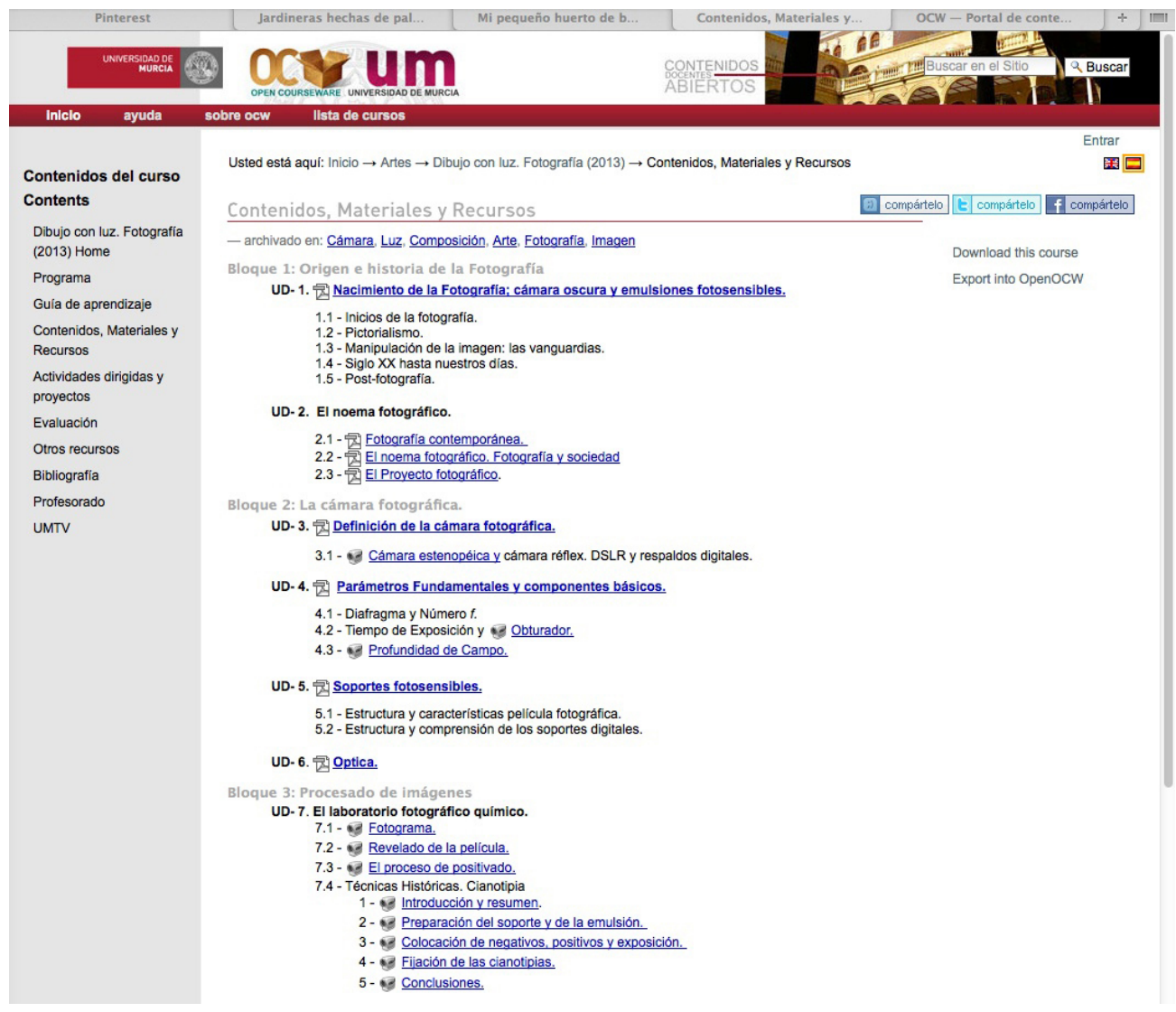

Figura 8.Portal OCW de la UM. Asignatura Dibujo con luz. Fotografía 2013.

(Captura de Pantalla de los Contenidos, Materiales y Recursos). 


\section{Primeros resultados y conclusiones}

El presente artículo se presentaba como un primer análisis de resultados arrojados por el proyecto El uso de las TIC aplicadas al aprendizaje autónomo del alumno en la enseñanza universitaria de fotografía. Elaboración de un aula didáctica virtual para la asignatura y estudio de resultados de mejora en la adquisición de habilidades y competencias tras cuatro años de realización. No obstante, y como se ha comentado a lo largo de estas páginas, las distintas fases del proyecto así como el cambio en las herramientas de Campus Virtual de la UM, de SUMA al Aula Virtual, plantea ciertas complicaciones en lo que a resultados arrojados se refiere. La antigua herramienta SUMA nació en 1998 y no fue sustituida hasta 2010 por el Aula Virtual, siendo la primera muy escasa en cuanto a los datos estadísticos de uso por parte de alumnos y profesores se refiere. Con la llegada del Aula Virtual se implementó una potente herramienta de estadísticas de uso que proporcionó a los investigadores una batería de datos contrastables a partir del curso 2011/12. En los cursos que comprenden del 2009 a 2011 los datos de seguimiento eran muy escuetos, por lo que la interpretación de los resultados, esos dos primeros años, no posee la solidez que en cursos posteriores. A pesar de eso consideramos que, dados otros indicadores y los abundantes datos aportados por los cursos posteriores, la tendencia mostrada en las conclusiones es irrefutable.

Dadas las características de esta publicación y las limitaciones de espacio nos es imposible mostrar todos los datos y gráficas obtenidos, pero hemos considerado significativo mostrar un breve resumen de los mismos, curso a curso.

\begin{tabular}{|c|c|c|c|c|c|c|}
\hline \multirow{2}{*}{$\begin{array}{l}\text { Nuevos Foros } \\
\text { Incluídos }\end{array}$} & $\begin{array}{l}\text { Número de Nuevos } \\
\text { Foros Creados: }\end{array}$ & $\begin{array}{l}\text { Númerode Alumnos } \\
\text { que Crearon Foros: }\end{array}$ & & & & \\
\hline & 2 & $2(2,06 \%)$ & & & & \\
\hline \multirow[t]{2}{*}{ Lecturas en Foros } & $\begin{array}{c}\text { Número de Lecturas } \\
\text { Totales: }\end{array}$ & $\begin{array}{l}\text { Número de Foros } \\
\text { Diferentes Le_dos: }\end{array}$ & $\begin{array}{l}\text { Número de Alumnos } \\
\text { que Leyeron los } \\
\text { Foros: }\end{array}$ & $\begin{array}{l}\text { Número Medio de } \\
\text { Lecturas Por Foro: }\end{array}$ & $\begin{array}{l}\text { - Foro M_s } \\
\text { Le_do (63Lecturas): }\end{array}$ & $\begin{array}{l}\text { Le_- Foro Menos } \\
\text { Lo (51Lecturas): }\end{array}$ \\
\hline & 114 & 2 & $52(53,61 \%)$ & & $\begin{array}{l}\text { papel fotografico, como lo } \\
\text { hacemos?(para el grupo A) }\end{array}$ & $\begin{array}{l}\text { Papel fotografico } \\
\text { demasiado caro }\end{array}$ \\
\hline \multirow{2}{*}{$\begin{array}{l}\text { Nuevas } \\
\text { Participaciones de } \\
\text { Foros }\end{array}$} & $\begin{array}{c}\text { Número de Nuevas } \\
\text { Participaciones de Foros } \\
\text { Creadas: }\end{array}$ & $\begin{array}{l}\text { Número de Alumnos } \\
\text { que Crearon } \\
\text { Participaciones de } \\
\text { Foros: }\end{array}$ & & & & \\
\hline & 2 & $1(1,03 \%)$ & & & & \\
\hline \multirow{2}{*}{$\begin{array}{l}\text { Lecturas de } \\
\text { Participaciones de } \\
\text { Foros }\end{array}$} & $\begin{array}{c}\text { Númerode Lecturas } \\
\text { Totales: }\end{array}$ & $\begin{array}{l}\text { Número de } \\
\text { Participaciones de } \\
\text { Foros Diferentes } \\
\text { Leídas: }\end{array}$ & $\begin{array}{c}\text { Número de Alumnos } \\
\text { que Leyeron las } \\
\text { Participaciones de } \\
\text { Foros: }\end{array}$ & $\begin{array}{c}\begin{array}{c}\text { Número Medio de } \\
\text { Lecturas Por } \\
\text { Participacion de Foro: }\end{array}\end{array}$ & $\begin{array}{l}\text { Participacion de Foro M_s } \\
\text { Le_da (18Lecturas): }\end{array}$ & $\begin{array}{l}\text { - Participacion de Foro } \\
\text { Menos } \\
\text { Le_da (17Lecturas): }\end{array}$ \\
\hline & 35 & $2(100 \%)$ & $17(17,53 \%)$ & 17,5 & Asunto de la Participaci_n & Asunto de la Participaci_n \\
\hline \multirow{2}{*}{$\begin{array}{l}\text { Lecturas de Anuncios } \\
\text { del Tablón }\end{array}$} & $\begin{array}{l}\text { Número de Lecturas } \\
\text { Totales: }\end{array}$ & $\begin{array}{l}\text { Número de Anuncios } \\
\text { Diferentes Leíos: }\end{array}$ & $\begin{array}{c}\text { Número de Alumnos } \\
\text { que Leyeron los } \\
\text { Anuncios: }\end{array}$ & $\begin{array}{c}\text { Número Medio de } \\
\text { Lecturas Por Anuncio: }\end{array}$ & $\begin{array}{l}\text { Anuncio M_s } \\
\text { Le_do (129Lecturas): }\end{array}$ & $\begin{array}{l}\text { Anuncio Menos } \\
\text { Le_do (3Lecturas): }\end{array}$ \\
\hline & 1853 & $35(94,59 \%)$ & $97(100 \%)$ & 50,08 & $\begin{array}{l}\text { Comienzo de clases Dibujo } \\
\text { con luz. Grupos C y D }\end{array}$ & $\begin{array}{c}\text { ConcuRso Cartel Facultac } \\
\text { de C. del Trabajo }\end{array}$ \\
\hline \multirow{2}{*}{ Nuevas Tutorías } & $\begin{array}{l}\text { Número de Nuevas } \\
\text { Tutorias Creadas: }\end{array}$ & $\begin{array}{l}\text { Número de Alumnos } \\
\text { que Crearon Tutorias: }\end{array}$ & & & & \\
\hline & 151 & $52(53,61 \%)$ & & & & \\
\hline \multirow[t]{2}{*}{ Lecturas en Tutorías } & $\begin{array}{l}\text { Número de Lecturas } \\
\text { Totales: }\end{array}$ & $\begin{array}{l}\text { Número de Tutorías } \\
\text { Diferentes Leídas: }\end{array}$ & $\begin{array}{l}\text { Númerode Alumnos } \\
\text { que Leyeron las } \\
\text { Tutorías: }\end{array}$ & $\begin{array}{l}\text { Número Medio de } \\
\text { Lecturas Por Tutoria: }\end{array}$ & $\begin{array}{c}\text { Tutor_a M_s } \\
\text { Le_da (7Lecturas): }\end{array}$ & $\begin{array}{l}\text {-Tutor_a Menos } \\
\text { Le_da (1Lecturas): }\end{array}$ \\
\hline & 108 & $69(16,67 \%)$ & $32(32,99 \%)$ & 0,26 & Re:laboratorio & fotos reflex \\
\hline
\end{tabular}

Figura 9.Sitio 1355 Dibujo con luz. Fotografía. Esquema de entradas por herramientas. Periodo de tiempo completo. Rol seleccionado: Estudiante.Entorno SUMA 2.0. Curso 2009/10. 
1355: DIBUJO CON LUZ: FOTOGRAFÍA [10/11]

\begin{tabular}{|c|c|c|c|c|c|c|}
\hline \multirow[b]{2}{*}{$\begin{array}{c}\text { Lecturas en } \\
\text { Faqs }\end{array}$} & $\begin{array}{l}\text { Número de } \\
\text { Lecturas } \\
\text { Totales: }\end{array}$ & $\begin{array}{l}\text { Número de } \\
\text { Faqs } \\
\text { Diferentes } \\
\text { Leídas: } \\
\end{array}$ & $\begin{array}{l}\text { Número de } \\
\text { Alumnos que } \\
\text { Leyeron las } \\
\text { Faqs: } \\
\end{array}$ & $\begin{array}{l}\text { Número } \\
\text { Medio de } \\
\text { Lecturas } \\
\text { Por Faq: }\end{array}$ & Le_da (1Lecturas): & \\
\hline & 1 & $1(100 \%)$ & $1(0,95 \%)$ & 1 & $\begin{array}{c}\text { Hola Borja, soy Ana } \\
\text { Bel_n Gil, alumna del } \\
\text { grupo } 1 \_ \text {D, es para } \\
\text { pedirte una tutor_a } \\
\text { por el trabajo de fin } \\
\text { de curso, si es pronto } \\
\text { a_n me dices. Recibe } \\
\text { un cordial saludo. }\end{array}$ & \\
\hline \multirow[t]{2}{*}{$\begin{array}{c}\text { Lecturas de } \\
\text { Anuncios del } \\
\text { Tablón }\end{array}$} & $\begin{array}{l}\text { Número de } \\
\text { Lecturas } \\
\text { Totales: }\end{array}$ & $\begin{array}{l}\text { Número de } \\
\text { Anuncios } \\
\text { Diferentes } \\
\text { Leídos: }\end{array}$ & $\begin{array}{l}\text { Número de } \\
\text { Alumnos que } \\
\text { Leyeron los } \\
\text { Anuncios: }\end{array}$ & $\begin{array}{c}\text { Número } \\
\text { Medio de } \\
\text { Lecturas } \\
\text { Por } \\
\text { Anuncio: }\end{array}$ & $\begin{array}{c}\text { Anuncio M_s } \\
\text { Le_do (278Lecturas } \\
\text { ): }\end{array}$ & $\begin{array}{c}\text { - Anuncio } \\
\text { Menos } \\
\text { Le_do (1 Lectur } \\
\text { as): }\end{array}$ \\
\hline & 6047 & $68(97,14 \%)$ & $106(100,95 \%)$ & 86,39 & Practica Estenopeica & $\begin{array}{c}\text { Conferencia } \\
\text { Alberto Adsuara }\end{array}$ \\
\hline \multirow{2}{*}{$\begin{array}{c}\text { Lecturas de } \\
\text { Anuncios del } \\
\text { Tablón }\end{array}$} & $\begin{array}{c}\text { Número de } \\
\text { Nuevas } \\
\text { Tutorías } \\
\text { Creadas: } \\
\end{array}$ & $\begin{array}{c}\text { Número de } \\
\text { Alumnos que } \\
\text { Crearon } \\
\text { Tutorías: } \\
\end{array}$ & & & & \\
\hline & 179 & $60(57,14 \%)$ & & & & \\
\hline \multirow[t]{2}{*}{$\begin{array}{c}\text { Lecturas en } \\
\text { Tutorías }\end{array}$} & $\begin{array}{l}\text { Número de } \\
\text { Lecturas } \\
\text { Totales: }\end{array}$ & $\begin{array}{l}\text { Número de } \\
\text { Tutorías } \\
\text { Diferentes } \\
\text { Leídas: }\end{array}$ & $\begin{array}{l}\text { Número de } \\
\text { Alumnos que } \\
\text { Leyeron las } \\
\text { Tutorías: }\end{array}$ & $\begin{array}{c}\text { Número } \\
\text { Medio de } \\
\text { Lecturas } \\
\text { Por Tutoría: }\end{array}$ & $\begin{array}{c}\text { Tutor_a M_s } \\
\text { Le_da (6Lecturas): }\end{array}$ & $\begin{array}{c}\text { Tutor_a } \\
\text { Menos } \\
\text { Le_da (1 Lectur } \\
\text { as): }\end{array}$ \\
\hline & 185 & $107(20,23 \%)$ & $45(42,86 \%)$ & 0,35 & $\begin{array}{l}\text { Re:Re:Re:Re:cambio } \\
\quad \text { hora de tutoria }\end{array}$ & $\begin{array}{c}\text { Re:Texto del } \\
\text { Asunto de la } \\
\text { Tutor_a }\end{array}$ \\
\hline
\end{tabular}

Figura 10.Entorno SUMA 2.0. Curso 2010/11.

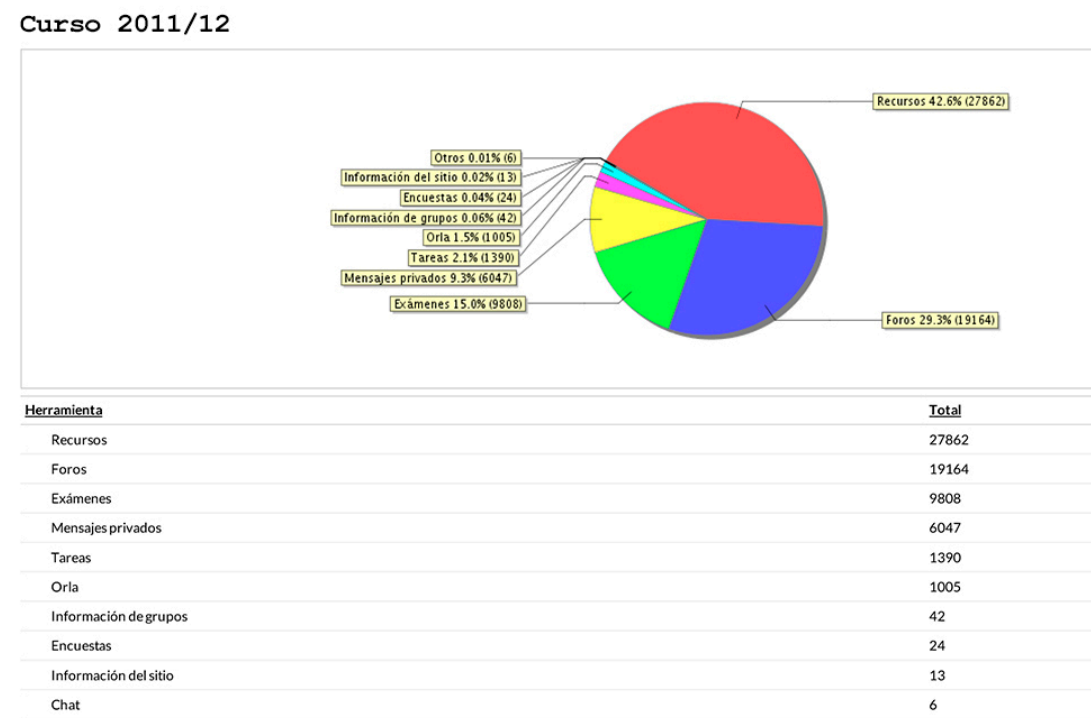

Figura 11. Entorno Aula Virtual. Curso 2011/12. 


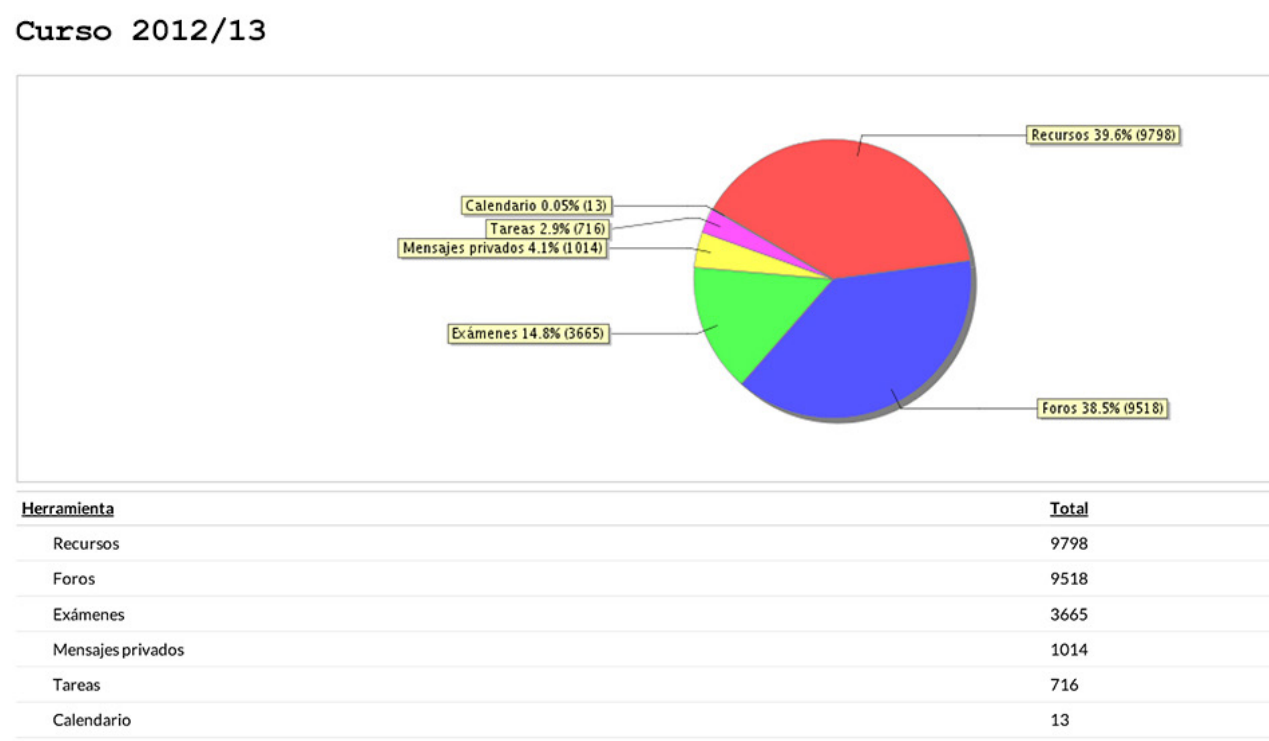

Figura 12.. Entorno Aula Virtual. Curso 2012/13.

\section{Conclusiones}

La adquisición de competencias, el cumplimiento de los objetivos así como el desarrollo del temario experimentó un notable avance, dejando clara evidencia de que las acciones tomadas van por el buen camino.

La enseñanza universitaria en Bellas Artes, gracias al sistema de enseñanza implantado desde su transformación a estudios universitarios, partía de una envidiable posición a la hora de adaptarse al EEES, lo que ha supuesto un menor esfuerzo docente para el profesorado y los centros. Sin duda la implantación del Grado ha supuesto una drástica reducción de créditos presenciales y una aparente falta de tiempo para desarrollar los programas. Hay que añadir, además, una evidente falta de medios materiales y técnicos para la implantación del EEES. El desarrollo del proyecto no ha estado exento de retos y dificultades.

El profesorado universitario necesita adaptarse al nuevo panorama y replantear su tradicional sistema de enseñanza, haciendo un mayor uso de las nuevas herramientas. Es necesario revisar el temario tradicional de la enseñanza en fotografía, para adaptarnos a las actuales circunstancias. Este replanteamiento ha de basarse en el aprendizaje de la fotografía de manera transversal. Se deben utilizar con un mayor aprovechamiento, las herramientas que el EEES fomenta como: el trabajo autónomo del alumno, las nuevas tecnologías y el aprendizaje colaborativo. El alumno deberá a su vez tener una mayor responsabilidad en su formación a través del ya mencionado trabajo autónomo, algo que exige el EEES y que, sin duda, debemos ir implantando en nuestra manera de enseñar. La tutoría, cobra un nuevo valor en los Grados, pasando a ser una herramienta fundamental para este nuevo tipo de enseñanza.

Tras cuatro años de implantación y desarrollo de nuestro proyecto de innovación docente, los datos arrojados por las estadísticas de uso demuestran un aumento 
significativo en la utilización de las herramientas puestas a disposición de los alumnos. Año tras año podemos observar claramente cómo los estudiantes han asimilado las distintas iniciativas en enseñanza virtual puestas a su disposición. Contrastando los datos de uso, visitas y descargas, con los resultados académicos de tasa de suspensos y aprobados, queda demostrado como podemos ver en la figura 13A que, a medida que aumentan los primeros, aumentan la tasa de aprobados, la nota media de la asignatura y disminuye la tasa de suspensos. Esta tendencia, expresada en la gráfica inferior se ve confirmada por los resultados estadísticos del curso 2013/14 que, sin haber finalizado, muestran un mayor índice de visitas, descargas y actividad que en los cursos precedentes en el mismo periodo, con unos resultados académicos proyectados ascendentemente.

La falta de medios ha ralentizado mucho los trabajos de implantación del presente proyecto y el programa planteado inicialmente se ha visto seriamente comprometido con sucesivos retrasos. La nula financiación y apoyo institucional en la traducción de los materiales ha obligado al equipo de trabajo a replantear la implantación de estas herramientas en enseñanzas anglosajonas o a evaluar los resultados obtenidos por los alumnos de intercambio de programas Erasmus o ILA. No obstante la fase de trabajo que ahora comienza, con la implantación de estas técnicas en centros nacionales e internacionales de habla hispana se prevé esperanzadora.

Recientemente el portal OCW de la asignatura Dibujo con Luz. Fotografia ha sido reconocido con una de las dos menciones en el VII edición de los PREMIOS MECDUNIVERSIA a la iniciativa OpenCourseWare (OCW) 2013, otorgado por el Ministerio De Educación, Cultura y Deporte y el portal UNIVERSIA, lo que refuerza el trabajo realizado por el equipo que integra el proyecto y, junto con los resultados obtenidos hasta la fecha, da una sólida base para iniciar las siguientes acciones.

Nos encontramos en disposición de afirmar que la enseñanza universitaria en fotografía puede apoyarse en las herramientas docentes virtuales, favoreciendo éstas la adquisición de competencias generales, planteadas por el EEES y específicas de la materia. Este proyecto y los primeros resultados son buena prueba de ello, por lo que sin ningún género de dudas debemos continuar con su desarrollo y confirmar estas conclusiones con futuros resultados.

Contrastar los datos obtenidos en otros centros de enseñanza superior en los que se imparta la fotografía sería de vital importancia para el futuro desarrollo del proyecto de innovación, por lo que en ulteriores acciones, el equipo de trabajo debería centrarse en este aspecto del proyecto. 


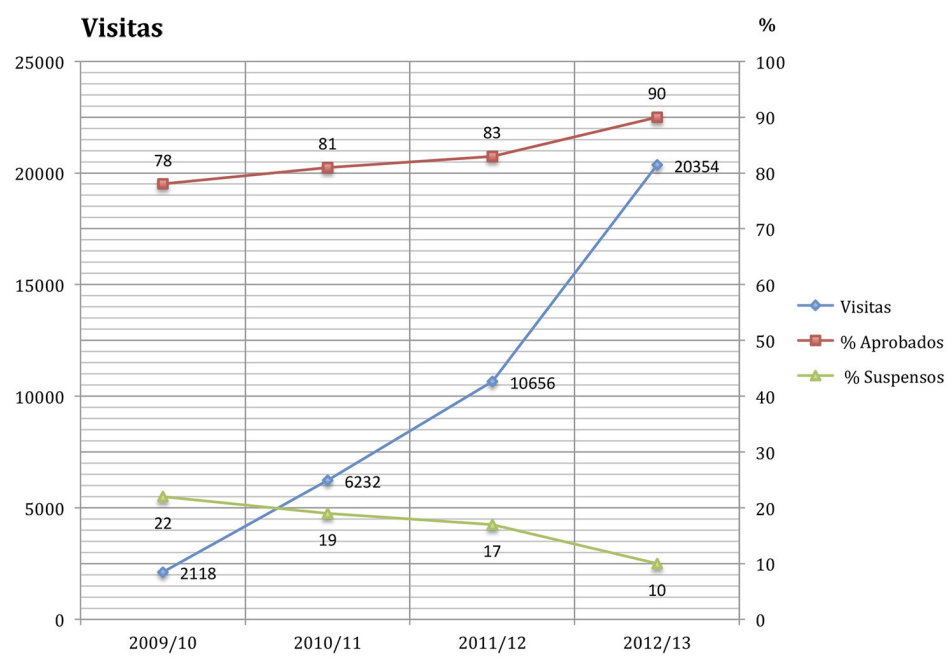

Nota Media

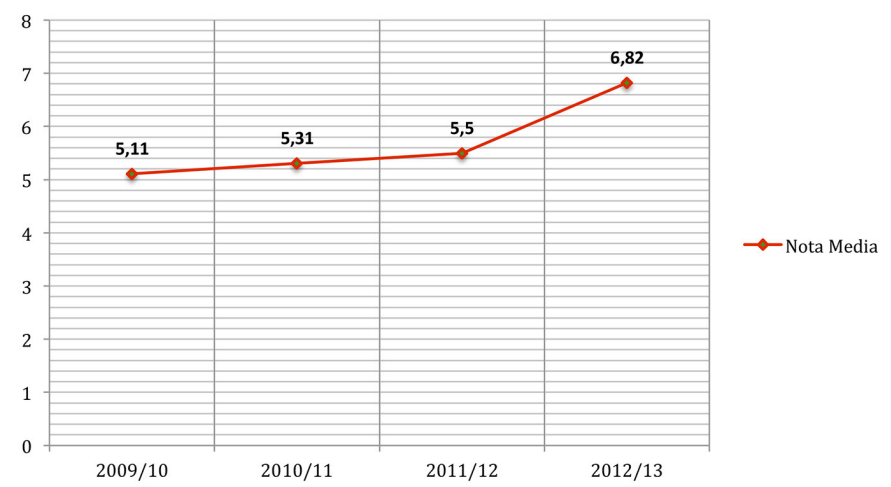

Figura 13A.Evolución gráfica durante los cuatro cursos estudiados. Número de entradas, aprobados y suspensos.

Figura 13B. Evolución nota media de la asignatura. (Cuadro de elaboración propia).

\section{Referencias}

Ariño Villarroya, A. (2009). El Movimiento Open. La creación de un dominio público en la era digital. Valencia: Universitat De Valencia. Servei De Publicacions.

Gobierno De España. Ley Orgánica 6/2001, de 21 de diciembre, de Universidades, Boletín Oficial del Estado, de 24 de diciembre de 2001, núm. 307, pp 49400-49425; (Ref. BOE-A-2001-24515).

Gobierno De España. Ley Orgánica 4/2007, de 12 de abril, por la que se modifica la Ley Orgánica 6/2001 de 21 de diciembre, de Universidades.Boletín Oficial del Estado, 13 de abril de 2007, núm. 89, pp 16241-16260.(Ref. BOE-A-2007-7786). 
Geser, G. ,ed. (2007) Open Educational Practices and Resources. OLCOS Roadmap 2012. Open e-Learning Content Observatory Services.

Gobierno De España; Unión Europea. Ministros Europeos de Enseñanza, (1999) Declaración de Bolonia. Declaración conjunta de los Ministros Europeos de Educación (19 de Junio de 1999) [En línea] http://www.eees.es/pdf/Bolonia_ES.pdf Consultado (25/11/2013).

Gobierno De España; Unión Europea. Ministros Europeos de Educación Superior. (2001) Declaración de Praga 2001. Hacia el área de la educación superior europea. Praga 19 de mayo de 2001. [En línea] http://www.eees.es/pdf/Praga_ES.pdf Consultado (20/11/2013).

Lessing, L. (2005). Por una cultura libre. Cómo los grandes medios de comunicación utilizan la tecnología y la ley para clausurar la cultura y controlar la creatividad. Madrid:Traficantes de sueños.

Tamayo, M. (1999). Metodología de la investigación. Bogotá: ICFES.

Wiley, D. A. (2000). Connecting learning objects to instructional design theory: A definition, a metaphor, and a taxonomy. In D. A. Wiley (Ed.), The Instructional Use of Learning Objects: Online Version.http://reusability.org/read/chapters/wiley.doc Consultado (05/12/2013). 
